\title{
RevistAleph
}

\section{MEU CONHECIMENTO DE HUMBERTO MATURANA}

\author{
Nelson Monteiro Vaz - UFMG.
}

Foto: Maturana e Vaz em Santiago, 2004.

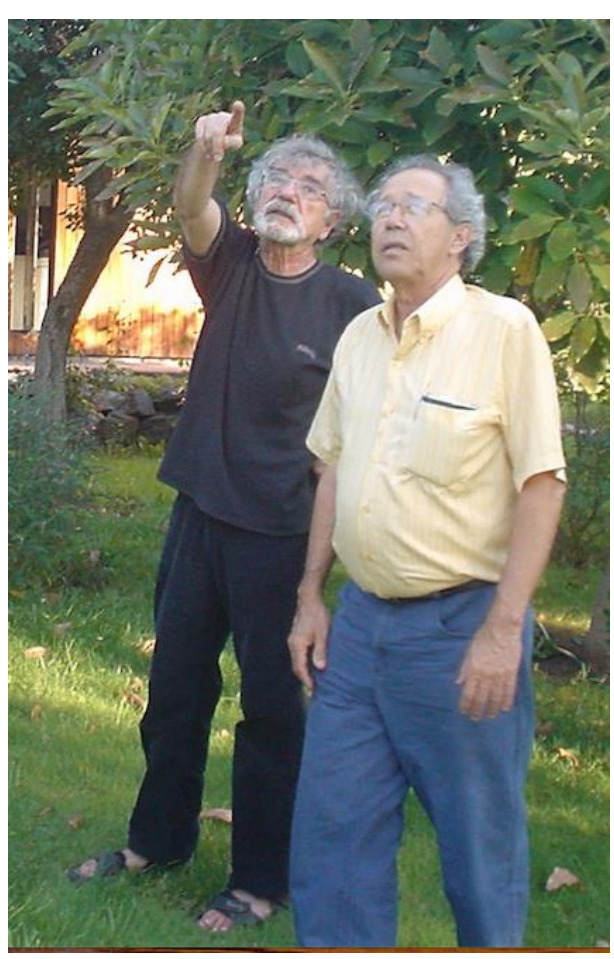

Quem leu Maturana e não se escandalizou, não entendeu. Ele faz as perguntas profundas e inevitáveis nas dúvidas de todos nós e de muitos pensadores, mas ele não se conforma em deixálas sem respostas. É possível não concordar com suas propostas e muitos não concordam, mas é impossível não entender o que ele propõe. Ele está interessado em explicar o que se passa com o observador humano em seu observar, em seu viver na linguagem. Neste processo, ele explica o que constitui uma explicação e o que a torna científica. Diz que a linguagem permite a comunicação mas não é a transmissão de informação simbólica, mas sim uma coordenação de condutas e, no caso humano, uma coordenação desta coordenação - um viver na linguagem que nos caracteriza como humanos. Diz que somos emocionais, como todos os animais, e não racionais como supomos. Quando era estudante de doutorado em Londres, J.Z.Young, seu mentor, preocupado, perguntou: "Por que você quer mudar tudo!?" Ele respondeu: "Eu não quero mudar tudo, mas tudo resulta mudado quando penso na biologia do conhecer." Esta frase volta e meia me comove: "Tudo resulta mudado", uma intuição de toda uma outra cosmologia que ele, afinal, desenvolveu gradualmente, como um artesanato.

Se faço as perguntas usuais - o que é a realidade? Quem somos nós - encontro-me em um mundo estranho, e neste mundo nós mesmos somos as coisas mais estranhas. 


\section{RevistAleph}

Se, por outro lado, acho que meu corpo tem que "dar conta" do que se passa comigo, encontro-me como minha biologia de ser vivo, de animal, de Homo sapiens, de pessoa na família, na sociedade. Encontro-me com a Biologia do Conhecer e da Linguagem. "A árvore do Conhecimento" (MATURANA; VARELA, 2001) é o livro mais popular sobre o tema e seu tratamento mais rigoroso está em "Autopoiesis and Cognition" (MATURANA; VARELA, 1980).

Antes de encontrar Humberto Maturana eu encontrei, fortuitamente, Francisco Varela, como descrevi em outro local (VAZ, 2011). Maturana e Varela ou, mais frequentemente, Varela e Maturana, são citados como criadores da "teoria da autopoiese" ou fundadores da "Escola de Santiago" de epistemologia. Estas duas denominações são enganosas e não se referem adequadamente à obra destes dois neurobiólogos e pensadores formidáveis. Isoladamente, a ideia de autopoiese, ou autocriação/manutenção, não se refere a nada que não já saibamos: os seres vivos estão entregues a si mesmos, são entidades autônomas. E a "Escola de Santiago" imagina um corpo coerente de conhecimentos e estes dois cientistas diferiam em pontos fundamentais de seu entendimento. Talvez a aproximação menos problemática a esta diferença seja a leitura das introduções que cada um deles escreveu, vinte anos depois, para a segunda edição do primeiro livro que escreveram juntos " De máquinas e seres vivos" (MATURANA, 2011 a; VARELA, 2011) e do artigo do editor que aponta estas diferenças (PAUCAR-CACERES; HARDEN, 2011). Varela é melhor descrito como autor da "neurofenomenologia" ou da teoria da "enação" (VARELA et al. 2003), enquanto que Maturana é o construtor principal da Biologia do Conhecer e da Linguagem (MATURANA, 1997). Varela, infelizmente, faleceu ainda jovem, em 2001; Maturana, 20 anos depois, em 6 de maio de 2021.

Intermediei a introdução de Varela à imunologia ao final dos anos 1970, e publicamos juntos um texto que marcou uma forte inflexão em minha carreira de imunologista experimental e teórico (Vaz and Varela, 1978). Quatro anos mais tarde, organizei um 


\section{RevistAleph}

simpósio para a SBPC, no qual Varela conheceu Antônio Coutinho e três ou quatro anos adiante estávamos os três presentes em Paris, na Unité d'Immunobiologie do Institute Pasteur. Em colaboração com Coutinho e sua equipe, na qual destaco a figura de John Stewart, Varela publicou então diversos textos teóricos de imunologia com base em uma grande riqueza de resultados experimentais produzidos pelo grupo de Coutinho. Maturana, por outro lado, nunca se referiu diretamente à imunologia, a não ser por um curto capítulo, em 2009. Neste capítulo ele afirma: "Se pensarmos o sistema imunitário como um sistema cognitivo, buscaremos explicá-lo e entendê-lo em termos cognitivos segundo o que pensamos que é um fenômeno cognitivo." E esta tem sido minha atividade e minha dificuldade desde os anos 1980, ou seja, mostrar que a atividade imunológica, ao contrário do entendimento usual, não é uma atividade cognitiva, mas sim uma parte da dinâmica estrutural de constituição dos seres vivos, assim como é o processo digestivo ou a respiração.

É irônico que não tenhamos-eu e Maturana — publicado nada juntos, embora nos referirmos um ao outro com carinho (MATURANA, 2011b). Em e-mails que trocamos em 2018, ele me dizia: "Recorda que não são nem os antígenos nem mesmo os anticorpos que indicam a recuperação de uma enfermidade, mas sim a recuperação da harmonia da autopoiese molecular" (MATURANA, 1978 - não publicado). Eu procurava uma maneira de falar da "harmonia da autopoiese molecular" a meus colegas imunologistas, porque esta não é uma linguagem biomédica. Hoje, me dou conta que é possível, sim, falar desta harmonia, mas não tenho mais o meu mestre para compartilhar esta alegria.

Um dos colaboradores importantes da obra de Maturana, coautor das incursões sobre a teoria evolutiva com a proposta da origem das espécies por deriva natural (MATURANA; MPODIZIS, 1992; 2000), que muito tem colaborado conosco. Jorge Mpodoziz se destaca também, internacionalmente, na neurobiologia.

\section{Referências}




\section{RevistAleph}

MATURANA, H. R., \& VARELA, F. J. Autopoiesis and Cognition. The Realization of the Living. Dodrecht: Reidel, 1980.

MATURANA, H. R., \& VARELA, F. El Arbol del conocimiento. Las bases biologicas del entendimiento humano. In (pp. 19-81). Santiago: Editorial Universitaria, 1984.

MATURANA, H. R., \& MPODOZIS, J. Origen de las espécies por medio de la deriva natural. Ó, La diversificación de los linajes a través de la conservación y cambio de los fenotipos ontogénicos. Santiago: Museo Natural de História Natural, 1992.

MATURANA, H. A ontologia da realidade. Belo Horizonte: Editora UFMG, 1997.

MATURANA, H., \& MPODOZIS, J. The origin of species by means of natural drift. Revista Chilena de Historia Natural, 73, 261-310, 2000.

MATURANA, H. O sistema imunitário. Em: Habitar Humano: em seis ensaios de Biologia Cultural (pp. 296). São Paulo, 2009.

MATURANA, H. R. Twenty years after. Origins and Implications of Autopoiesis. Preface to the Second Edition of De Máquinas y Seres Vivos. Constructivist Foundations, 6(3), 295-305, 2011.

MATURANA, H. R. Diseases: Loss of Inner Harmonies? Constructivist Foundations, 13(1), 609-620, 2011.

VARELA, F. J. Twenty years after. Preface to the Second Edition of De Máquinas y Seres Vivos. Constructivist Foundations, 6(3). 295-305. Maturana, H. R. (2011). Diseases: Loss of Inner Harmonies? Constructivist Foundations, 13(1): 609-610, 2011.

MPODOZIS, J. M. Function vs. Structure: The Immune System as a Case in Point. Construtivist Foundations, 13 (1); 607-609, 2011.

PAUCAR-CACERES, A., \& HARDEN, R. Introduction by the translators; Twenty years after. Preface to the Second Edition of De Máquinas y Seres Vivos. Constructivist Foundations, 6(3), 293-295, 2011.

VARELA, F.J.; THOMPSON, E.; ROSCH, E. A mente incorporada: ciências cognitivas e experiência humana. Porto Alegre: Editora Artme, 2003.

VAZ, N. M. Francisco Varela and the Immunological Self. Systems Research and Behavioral Science, 28, 696-703. DOI: 10.1002/sres.1126, 2011. 